\title{
HOMENAGEM
}

\section{Centenário de Deolindo Couto}

\author{
Marleide da Mota Gomes', Álvaro José de Lima Costa
}

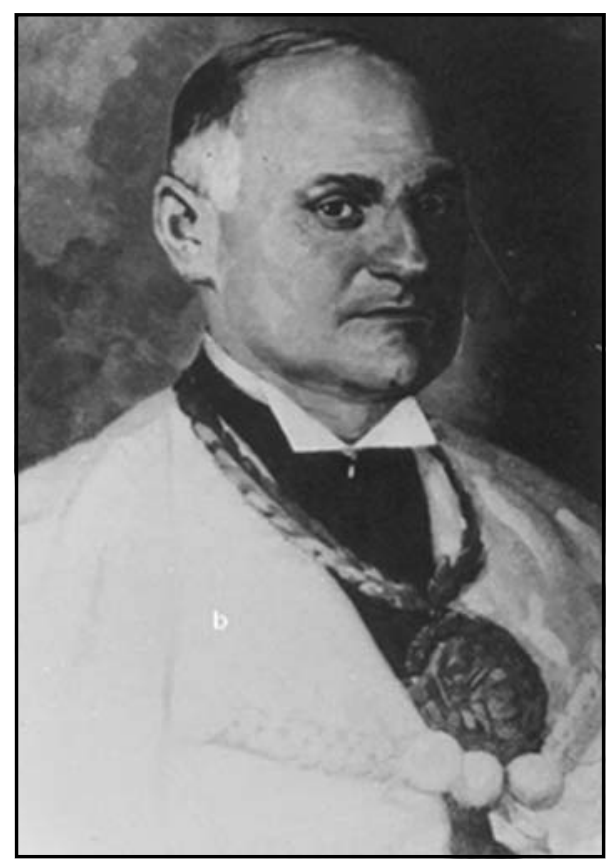

Deolindo Couto, reitor da Universidade do Brasil.

Segundo os léxicos, a expressão centenário aplica-se, entre outras acepções, ao transcurso de cem anos de dado evento, como o ciclo de uma vida, do nascimento à morte, então sobrevinda ao completar-se uma centúria. No caso presente, impõe-se lembrar o centenário de Deolindo Augusto de Nunes Couto (1902-1992), cujo passamento ocorreu aos 90 anos. A essa vida somam-se 10 anos de ausência, completando-se assim o prazo de um século. Estamos celebrando por dever moral e estima afetiva, a visão de 100 anos, não apenas do homem, mas também do seu tempo e lugar.

Deolindo Couto nasceu em 11 de março de 1902, em Teresina, no Piauí, e faleceu no Rio de Janeiro, a 29 de maio de 1992, mas teve infância e adolescência no vizinho estado do Maranhão. Era filho de Maria R. de Nunes Couto e do magistrado e professor de Direito, desembargador Henrique José Couto.
Teve ele sua formação neurológica na Escola de Antonio Austregésilo, o fundador da Neurologia Brasileira (Fig 1). Sempre distinguido em primeiro lugar nas lides acadêmicas em que se empenhava, foi livre-docente de Clínica Médica e de Neurologia nas Faculdades de Medicina do Rio de Janeiro, da Escola de Medicina e Cirurgia e da Faculdade Fluminense de Medicina, assumindo, em 1942, a chefia da $13^{\text {a }}$ Enfermaria da Santa Casa de Misericórdia, onde um de nós foi admitido como postulante ao cargo de interno de Clínica Médica, mediante sério compromisso de assiduidade e dedicação. O mestre dizia com relação ao neófito que se candidatava, que o empenho no trabalho e no estudo é dote que não se desgasta, e alumia a noite da velhice, a qual, aliás, acabou por Ihe alcançar sem todavia aclarar as sombras que descem continuamente. $O$ nosso mestre era exigente e às vezes firme nas suas cobranças de

${ }^{1}$ Professora Adjunta de Neurologia da Faculdade de Medicina da Universidade Federal do Rio de Janeiro, Rio de Janeiro RJ, Brasil (UFRJ); ${ }^{2}$ Professor Titular aposentado de Neurologia da Faculdade de Medicina da UFRJ. 


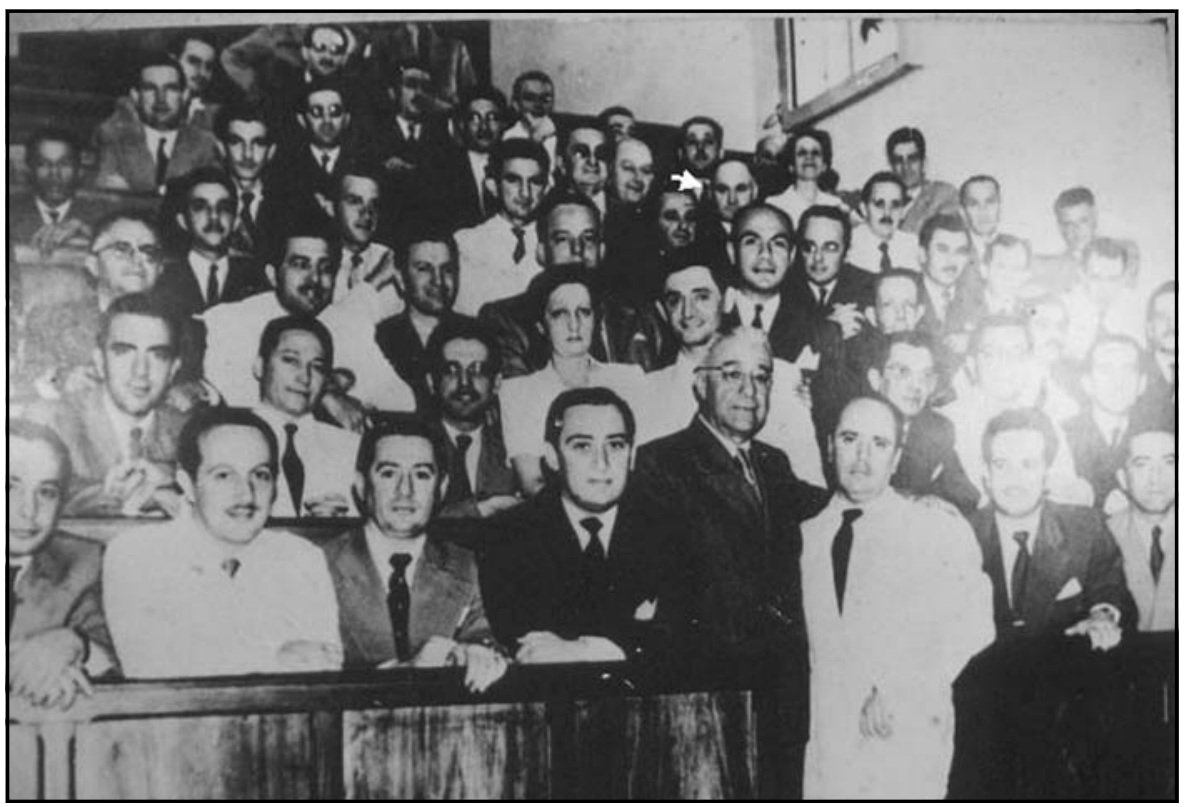

Fig 1. Deolindo Couto e sua Escola de origem sob o comando de Antonio Austregésilo.

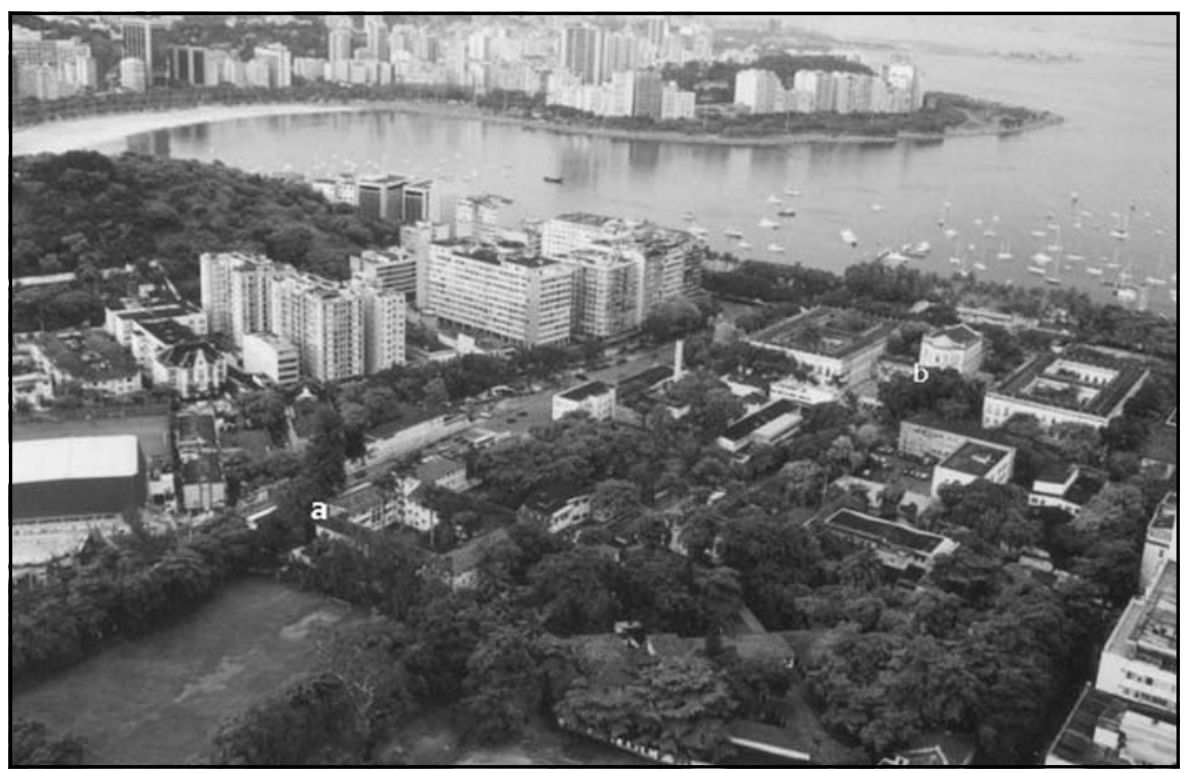

Fig 2. Campus da Praia Vermelha da UFRJ. $a$, Instituto de Neurologia; $b$, Reitoria da UFRJ, antigo Hospício de D. Pedro II.

trabalho e correção, no vestir, no falar e na execução das tarefas. Na sua Universidade, chegou ele ao posto máximo hierárquico, a de Reitor. Foi também Presidente do Conselho Federal de Educação, além de vice-reitor, professor emérito e membro do ConseIho Universitário da Universidade do Brasil e do Conselho Federal de Cultura.

Não era Deolindo Couto um mestre contemplativo. O seu dinamismo excedeu a Medicina, levando-o a múltiplas atividades intelectuais, cujo topo consubstanciou-se no seu ingresso na Academia Brasileira de Letras. Nela se destacou pela correção da linguagem, precisão vernacular e conhecimento profundo da obra de Camilo Castelo Branco. Foi, Deolindo Couto, eleito sete vezes Presidente da Academia Nacional de Medicina, "honrando, sob todos os ângulos, a ciência e a cultura do nosso país". O reconhecimento de sua influência nessa Casa é tão grande que ela é também conhecida como a casa dos Coutos, de Miguel a Deolindo. A sua obra científica, como também a literária, não se perpetuou através de registros numerosos. Ficaram mais a impressão do seu discurso e a verve espontânea. O concurso a que se submeteu para professor catedrático 


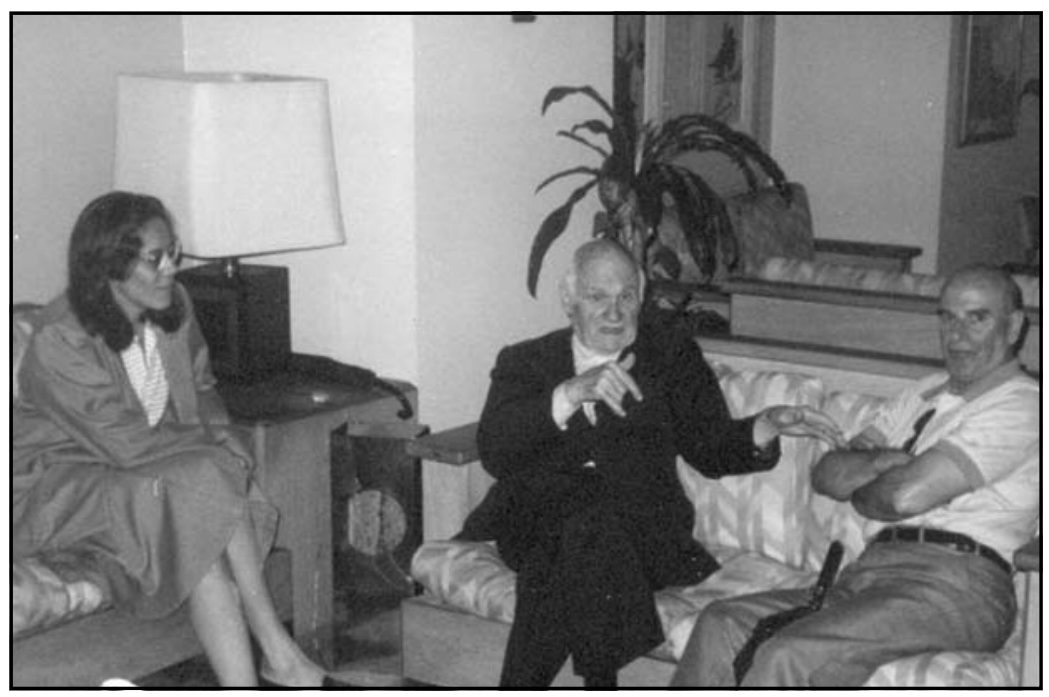

Fig 3. Deolindo Couto em convívio social.

da Universidade do Brasil, em 1945, e por ocasião de sua jubilação, em 1972, versaram temas assemelhados, com demonstração da competência do grande orador. Na primeira ocasião, abordou os efeitos da cirurgia sobre a via piramidal e o tremor parkinsoniano. Na segunda, discorreu sobre Doença de Parkinson, com ênfase na fisiopatogenia e levodoterapia, de introdução médica recente. 0 mestre também foi professor catedrático de Neurologia da Escola de Medicina e Cirurgia.

Brioso e audaz, construiu o Instituto de Neurologia da Universidade do Brasil, o "mais completo e perfeito que já vi", segundo as palavras de Mario Gazzano, catedrático de Neurologia da Universidade de Roma. Vários outros eminentes neurologistas de reconhecida notoriedade visitaram o Instituto e deixaram as suas boas impressões no seu livro de visitas. O Instituto e seu diretor também tinham prestígio político. O presidente Getúlio Vargas chegou a visitar o Centro Neurológico, entre outros políticos eminentes. O Instituto de Neurologia tem seu lastro nas bases legadas pelo antecessor, na cátedra de Neurologia, vale dizer, Antonio Austregésilo, em áreas do antigo Hospício de D. Pedro II (Fig 2), próximo da antiga sede da Faculdade de Medicina, edificada na Praia Vermelha, fundada aliás por ocasião da chegada do príncipe regente, D. João VI, ao Brasil. Lembra-se também que em boa parte da gestão de Deolindo Couto, o Rio de Janeiro era capital federal e ainda vigia a figura do catedrático, de grande poder. A Universidade do Brasil era ímpar no seu prestígio político e acadêmico. Assim, entende-se que o grande homem expressou a sua revolucionária obra tendo como lastro a sua época e lugar, em consórcio engrandecedor para a nossa Sociedade Neurológica. Menciona-se também que é de iniciativa de
Deolindo Couto o Jornal Brasileiro de Neurologia, hoje denominado de Revista Brasileira de Neurologia.

Deve-se à criatividade de Deolindo Couto e de vários outros preceptores a fundação da Academia Brasileira de Neurologia, isto em 5 de maio de 1962, no próprio Instituto de Neurologia, quando então tornou-se o Patrono da novel Instituição, hoje no seu quadragésimo ano. Nesse encontro histórico, foram aprovados os estatutos da nova Academia, escolhida a primeira diretoria e agendada a primeira reunião. Pouco depois, a Academia passou a ter como órgão oficial divulgador o celebrado Arquivos de Neuro-Psiquiatria, criado em 1943 pelo eminente professor Oswaldo Lange, e hoje gerido pelo competente comando de Antonio Spina-França Netto, um dos oráculos da neurologia moderna do país.

Conclui-se assim que Deolindo Couto, personificação admirável da cultura intelectual, enfeixava em si o homem de letras, o exuberante neurólogo, o pensador, o político, e, sobretudo, o Mestre. Nessa qualidade, patenteava o vigor de sua formação técnica, através do requinte da sua palavra, fluente, clara, objetiva, permeada por inexcedível bom humor, chiste e facécias. Nós, os autores, nos comprazíamos de ter a oportunidade de conviver com essa personalidade, e somos saudosos desses tempos idos (Fig 3). Inteligente e erudito, comandava ou acompanhava, depois da jubilação, com genial simplicidade as reuniões clínicas dos Serviços de que era depositário, quando então tínhamos o regalo de acompanhar a transparência da sua argumentação, a organização metódica do raciocínio, a sabedoria do senso comum, a sagacidade dos arrazoados, tudo mediado por opulenta riqueza vocabular, sem qualquer pedanteria. Como na estrofe do Poeta, ali, então, retombavam hinos. 